\title{
Review
}

\section{Systematic Review on Knowledge and Awareness of Breast Cancer and Risk Factors Among Young Women}

\author{
Aeshah Hamdan Almutairi ${ }^{1,2}$ Shamsul Bahri Bin Md Tamrin ${ }^{1 *}$, Rahmita Wirza $^{3}$, Norliza Binti Ahmad ${ }^{4}$ \\ ${ }^{I}$ Department Environmental and Occupational Health, Faculty Medicine \& Health Sciences, University Putra Malaysia (UPM), \\ 43400, Serdang, Selangor, Malaysia \\ ${ }^{2}$ Department Public Health, Al-lith College of Health Sciences, Umm Al-Qura University, P.O. Box 3712, Mecca, Saudi Arabia \\ ${ }^{3}$ Department of Multimedia, Faculty of Computer Science and Information Technology, Universiti Putra Malaysia, UPM, \\ 43400, Serdang, Selangor Darul Ehsan, Malaysia \\ ${ }^{4}$ Department of Community Health, Faculty of Medicine and Health Sciences, Universiti Putra Malaysia, 43400 UPM Serdang, \\ Selangor, Malaysia
}

*Corresponding Author: Shamsul Bahri Bin Md Tamrin, E-mail: aan090@hotmail.com

\section{ARTICLE INFO}

Article history

Received: September 05, 2018

Accepted: December 19, 2018

Published: January 31, 2019

Volume: 7 Issue: 1

Conflicts of interest: None

Funding: None

Key words:

Breast cancer,

Awareness,

Knowledge,

Risk factor,

Young adults

\begin{abstract}
Introduction: Breast cancer is considered the primary cancer to affect women according to the global context. Due to its crucial escalation, it has become vital to inform the general population regarding breast cancer symptoms, risk factors and earlier detection methods. The main aim of the present study is to conduct a systematic review of breast cancer and the risk factors affecting young adult women. Methods: A systematic literature review was carried out to garner global studies on breast cancer risk factors as well as to understand the degree to which breast cancer and its associated risk factors are understood. The primary study included the exploration of databases and journal websites, PubMed, Google Scholar and Medline. The articles studied for the review was focused on the printed original English articles from the year 2008 to December, 2017. This review highlights the necessity for further studies regarding knowledge of breast cancer and its risk factors among young adult women are understood. Conclusion: Knowledge about breast cancer and its risk factors among young women was inadequate. Furthermore, cultural sensitivities should be adjusted to ensure optimal awareness among the public, in particular teenagers and young adult women. Intensive educational campaigns should be planned to increase breast cancer awareness in order to minimize the observed deficit of knowledge. The role of prevention and procedures to screen breast examinations in clinics as well as mammography should all be highlighted in order to achieve these goals and obtain the required data.
\end{abstract}

\section{INTRODUCTION}

Breast cancer (BC) stands to date as the most highly diagnosed cancer among females resulting in mortalities due to cancer globally. According to an average annual estimation, as of 2012 there exist approximately 1.7 million cases, of which 521,900 have resulted in death (1). Breast cancer makes up $25 \%$ of all cancer cases and $15 \%$ of all cancer deaths among women (2). Incidence rates of breast cancer vary significantly and indicate a marked geographical variation, with western countries accounting for the highest rates and Asia and Africa accounting for the lowest incidence rates (3).

Among females, breast cancer remains one of the most prevalent causes of mortality. Around $16 \%$ of females who die of cancer are breast cancer patients. Modifiable management approaches include maintenance of a healthy weight, regular exercise, and cutting down on alcohol consumption. On the other hand, these strategic approaches may not always get rid of many types of breast cancers. Therefore, the focus is on detecting breast cancer in the earlier stages in order to control and manage the critical enhancements and risk factors of breast cancer effectively (4).

The term risk factor refers to the increase of the probability of getting a disease (5). One of the strategies in stopping breast cancer is in informing women about the possible risk factors and symptoms of breast cancer (6). To exemplify this, the development of breast cancer, including age, hormone therapy, family history, extensive exposure to radiation and benign breast tumor should all be well understood among the female population. Additionally, it is important for women to possess knowledge about the different diagnostic approaches and examinations required for the appropriate identifica- 
tion of breast cancer (7). Early detection of breast cancer will provide the patient with a better diagnosis $(8,9)$ and as a result, it provides a better chance of survival (10).

Awareness of the importance of obtaining knowledge on breast health is both practical and achievable, which will help detecting breast cancer early and with a positive prognosis. Generally, the gap of proper knowledge, low education and ignorance act as the major causes behind late detection of breast cancer $(6,7)$.

Statistically, approximately $45 \%$ of all cancer within females aged between 25 and 49 years old could be attributed to breast cancers. The figure goes down to $35 \%$ within females aged between 50 and 74 years old within the UK (11). In the age ranges of 15 to 24, roughly 3.1 in a million in the UK are affected (12). Within the US, the chances of breast cancer among females is $0.5 \%$ for those less than 39 years old and $3.8 \%$ for females aged between 40 and 59 years of age (13). An international survey illustrated less awareness of breast cancer risk factors among the youth of 23 countries in contrast to older women (14). This fact highlights the importance of raising more awareness among the younger population, which is a viable tactic in spreading more awareness holistically among the public (15).

The period of adolescence results in major physical and mental changes, which provides the leeway to shape and form health behaviors which would carry on into their adulthood and later lives. As an example, if young women are taught about breast care then they can develop positive behaviors among themselves to undertake breast examination through which they will be able to identify the condition of their breasts. It will also encourage them to seek professional help when required (16). Taught health behaviors, such as breast self-examinations (BSE), may lead the way for women to improve their own health and promote this behavior amongst their peers in society (17). Amongst females in the younger generations, being taught about BSE earlier on instills a positive healthy which is likely to persevere throughout their adult lives and enable them to self-examination, adhere to clinical breast examination and mammography screening (18).

\section{Objective}

The aim is to conduct systematic review studies carried out on knowledge and awareness of breast cancer and its risk factors among young adults.

\section{MATERIALS AND METHODS}

On the basis of the number of studies accomplished worlwide on breast cancer, a systematic literature review was conducted regardless of the study design. The main study was focused on searching through databasse and journal websites, including PubMed, Google Scholar and Medline. The study was limited to original English articles that appeared in publications from December 2008 to December 2017. The major searched keywords were 'knowledge','awareness','breast cancer', 'risk factors' and 'young adults'. Words with similar definition to the aforementioned searched terms were also employed. Primary screening of studies were conducted by reviewing the titles and abstracts of the articles. The study excluded articles that were not focused on breast cancer and its effect on young adult women before the year, 2008. Secondary screening was conducted by examining the full text of the studies after passing the primary screening. Figure 1 shows the flowchart of the study selection criteria.

\section{RESULTS}

The study revealed 14 articles that employed the criteria noted above. Studies including both international and local were focused to review on knowledge of breast cancer and its risk factors among young adults. Table 1 provides a summary of the results. Studies have shown that knowledge about breast cancer and having belief in the efficacy of breast cancer screening were positively associated with having breast cancer screening behaviors $(3,19)$.

A Saudi Arabian study attempted to determine breast cancer awareness levels, by testing a sample population of 254 students from the medical field, aged between 19 and 28 years old with a mean age of 22 years old. Findings demonstrated the knowledge of breast cancer to be $(21.6 \%),(40 \%)$, $(33.4 \%)$ and $(5 \%)$ were standard, substandard, average and below average, respectively. This study suggested that the level of awareness of Breast cancer among Saudi Medical Students was very low (20). Similarly, Segni conducted a study among 368 students to determine their knowledge, attitude and practice (KAP) of breast self-examination (BSE) on a regular basis among female health science students of Adama Science and Technology University in Ethiopia. The results indicated that only $8.7 \%$ of them possessed reasonable knowledge while the rest $(91 \%)$ possessed satisfactory to below average knowledge of breast cancer. However, nearly all the respondents heard about breast cancer (21).

In the United Arab Emirates (UAE), a study investigated 492 women aged from 25-45 years old to determine their knowledge about breast cancer among young women. The findings revealed that averagely, only $51 \%$ of the participants were informed about breast cancer to some extent. Most $(89 \%)$ of them were aware of the fact that breast cancer was not uncommon and $45 \%$ believed that it normally affected females older than 40 years of age. A little more than half of them $(53 \%)$ had idea about the signs and symptoms and the rest $(57 \%)$ were aware of a breast lump indicating as a sign of breast cancer. The conclusion of the study reported that the overall knowledge of breast cancer among the respondents were below expectation. The steady increase in the incidence of breast cancer is alarming and constructive steps should be taken to raise awareness for breast cancer through informative and interactive education and campaigns worldwide (22). Likewise, In Malaysia, a cross-sectional study was conducted with 820 undergraduate female students to determine the knowledge of breast cancer and breast self-examination practice. Results indicated that the participants possessed below average knowledge on breast cancer and breast self-examination. Less than $20 \%$ of the participants practiced breast self-examination regularly. Knowledge of breast self-examination was found to have significantly associated with breast self-examination practice ( $\mathrm{p}=0.001)$. Generally, among young Malaysian female adults, breast self-examination practice was 


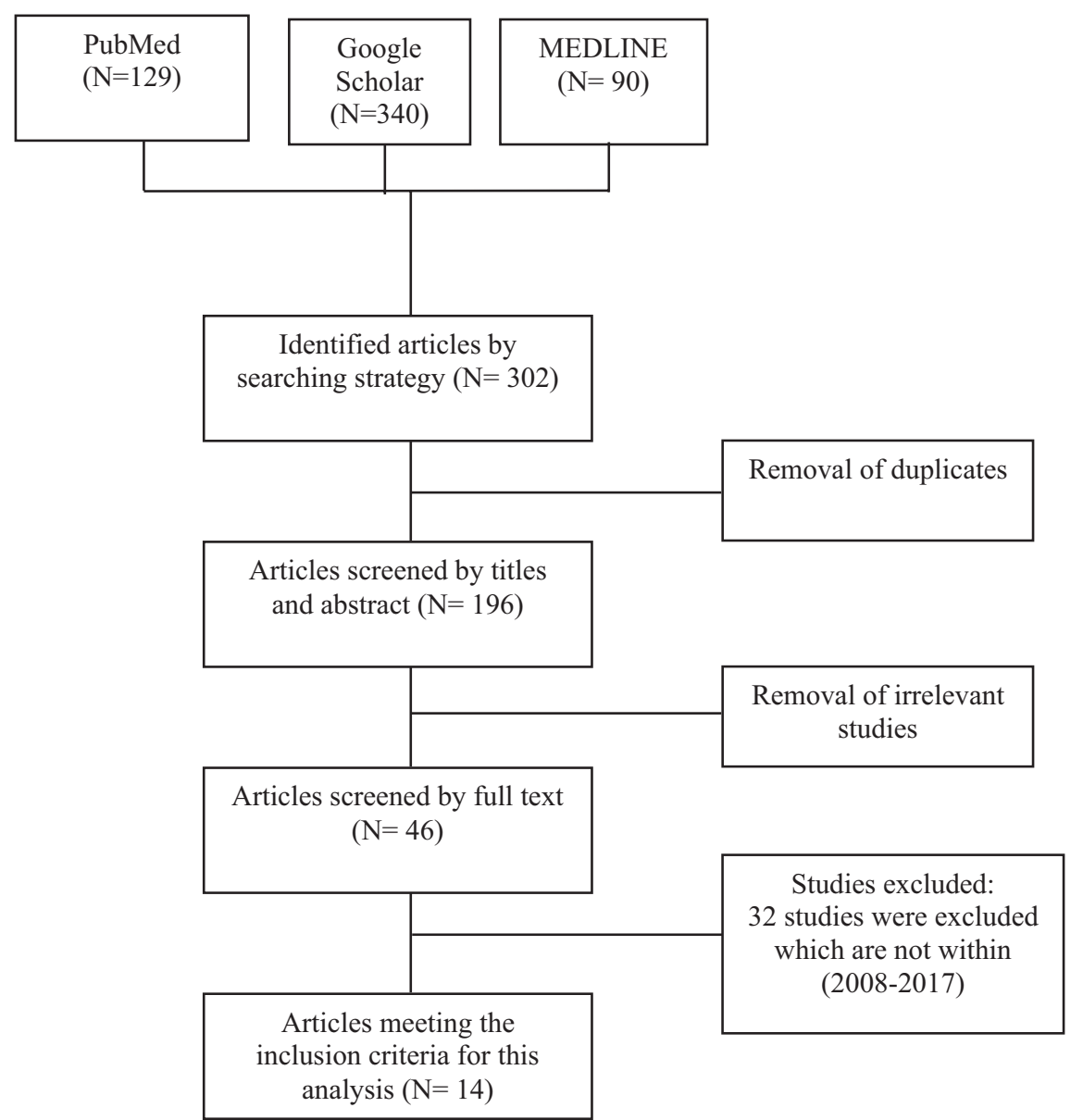

Figure 1: Flow diagram of the selection process of the study for systematic review on knowledge and awareness of breast cancer and its risk factors among young adults from 2008-2017

below average and knowledge of breast cancer was inadequate (23). Similarly, a cross-sectional survey was conducted involving 122,058 females around Shandong, Hebei, Jiangsu and Tianjin. It employed face-to-face interviews derived from a self-designed structured questionnaire. The results indicated below average awareness level of breast cancer among women in Eastern China. Only $18.6 \%$ of the participants possessed standard level of awareness while $81.4 \%$ possessed below average level of awareness (24). Following the similar way, a cross sectional study was conducted to determine the knowledge about breast cancer and breast self-examination practices among 384 women aged 18-52 years in the Iranian city of Hamadan. The finding indicated that the level of breast cancer knowledge possessed a significant association with breast self-examination practice $(\mathrm{p}=0.001)$. Hence, Iranian women's knowledge about breast cancer and breast self-examination practice was observed to be less than satisfactory. There should be education to increase greater awareness of the need for early detection of breast cancer (25).

Isara et al (2011) conducted a study among 300 female senior secondary school students, aged from 13-22 years in the municipal council area of Abuja,Nigeria. Results indicated that the respondents (57\%) possessed below average level of knowledge of breast cancer while $76 \%$ possessed negligible amount of knowledge about breast self-examination, mostly from mass media (26).
The result of a cross sectional study carried out in Saudi Arabia among 566 participants aged from 14 -52 years indicated that $75.4 \%$ of participants believed that breast cancer was hereditary. For early puberty and late menopause, 37\% agreed with the higher risk, for low and delayed child birth, (46\%), and for overweight and obesity, (37\%). Only 6.2\% agreed that breast feeding could lower the risk of breast cancer. There is a general lack of knowledge regarding several breast cancer risk factors among the northern Saudi community which urges the necessity of the immediate implementation of educational programs (27). In addition, a study of 559 women, aged from 20 - 40 years in Karachi, found that $69 \%$ of women believed that the use of contraceptives was closely related with breast cancer, $83 \%$ believed that breast feeding lowered the risk of breast cancer while $45 \%$ of women possessed no knowledge in undertaking effective precautions against breast cancer. Also, $60 \%$ believed breast cancer to be a genetic disease. Only $40 \%$ of women believed that the consumption of fruits and vegetables lowered the occurrence of breast cancer. The study concluded that overall women possessed minimal knowledge about breast cancer. Moreover, the study recommended increasing public awareness of the risk and screening modalities for breast cancer and breast self-examination utilizing the mass media (28).

Raed et al. (2014) conducted a study to determine how much the knowledge of Kuwaiti women regarding breast cancer, its risk factors, symptoms, and diagnostic procedures. 


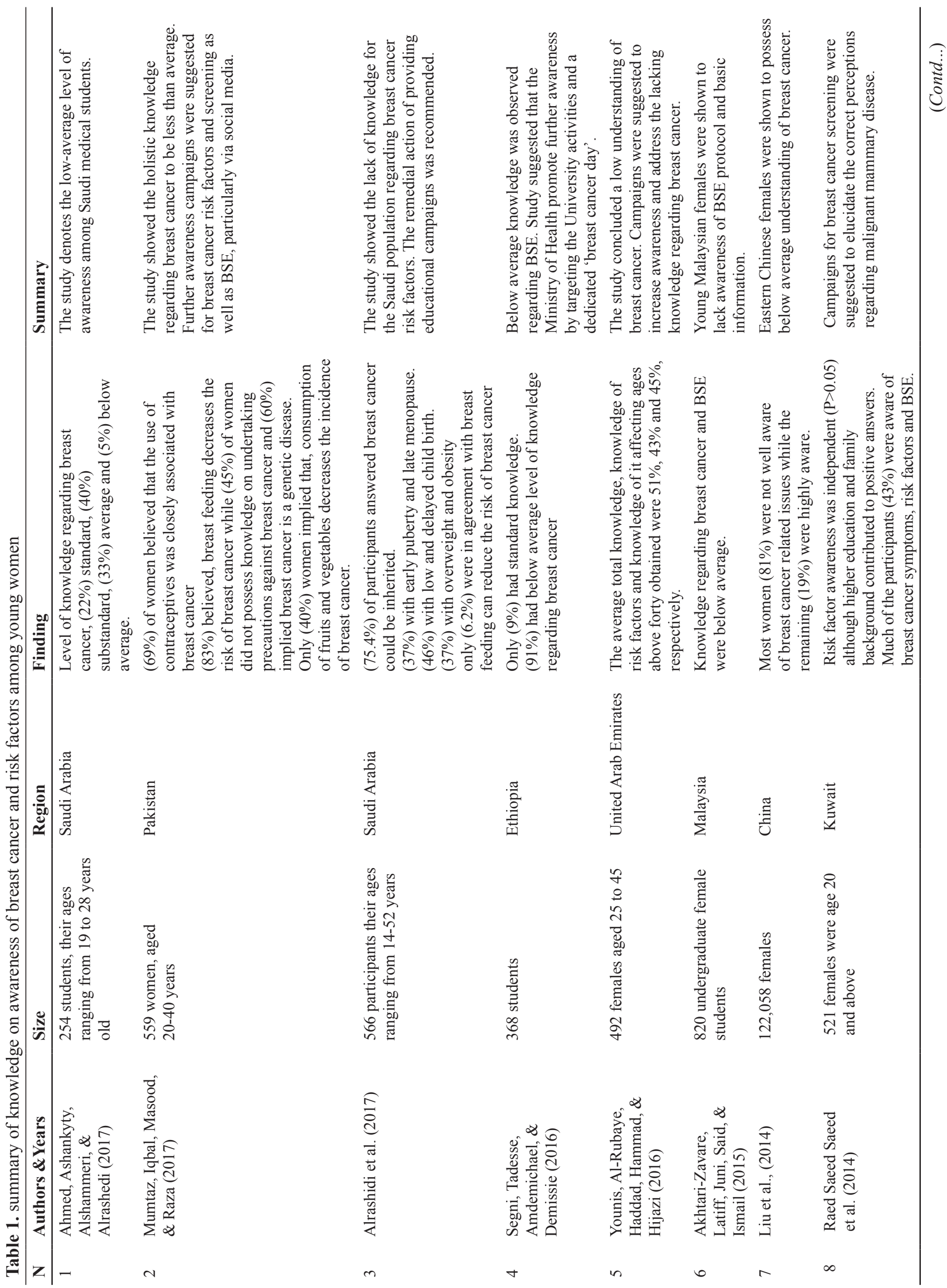




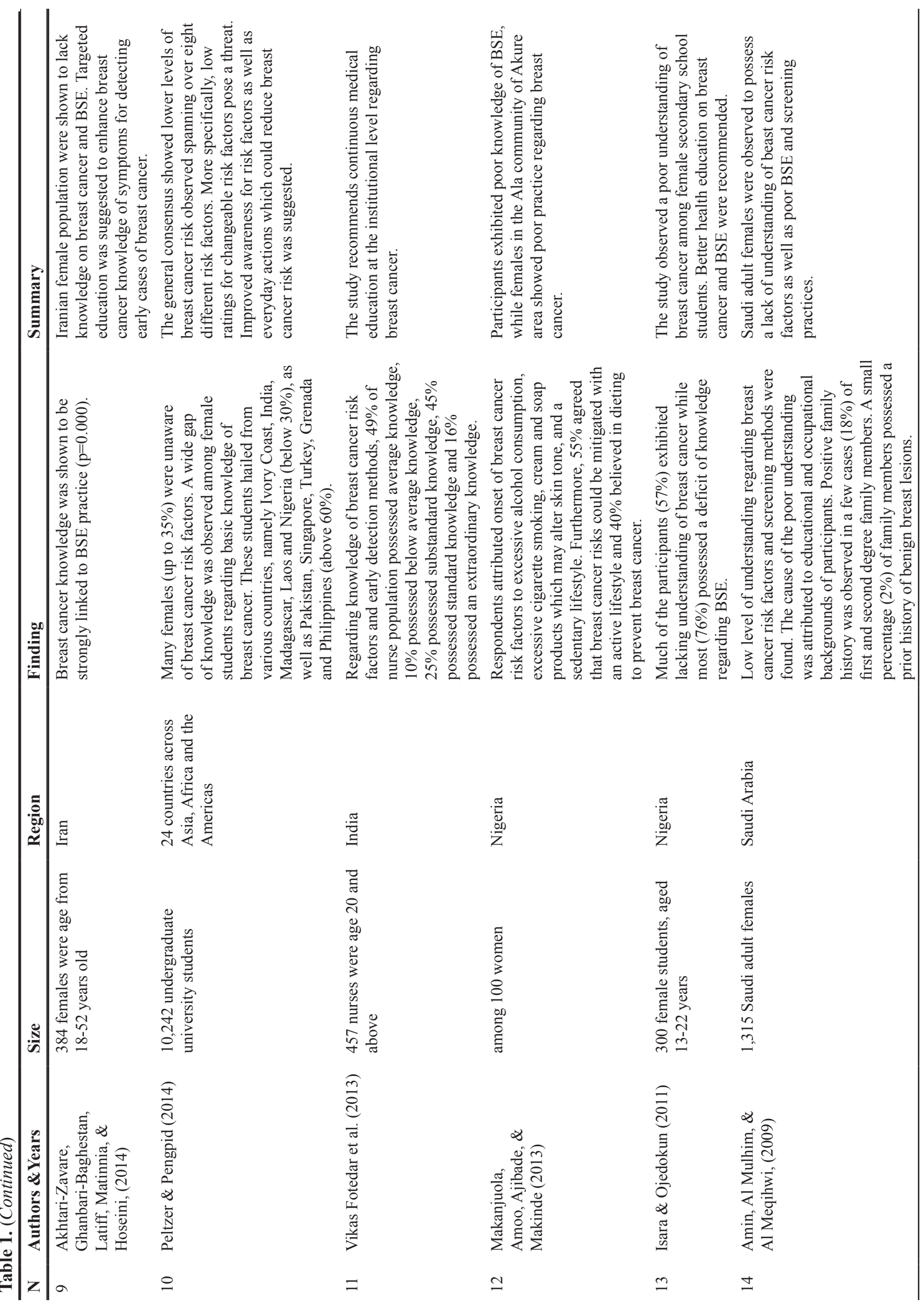


A sample of 521 women aged 20 and above was investigated and the findings revealed that $72 \%$ of participants' associated breast cancer factors with family history, and 69.7\% indicated abnormally enlarged breasts to an indication of breast cancer. About $84 \%$ of participants had heard about breast self-examination but only about half of that number knew anything about mammograms while only $22.2 \%$ expressed familiarity with diagnostic procedures. About $23 \%$ of the participants stated that the appropriate age to begin mammogram screen be roughly 40 years of age. Risk factor awareness was found to be not dependent on age groups, whereas higher education and family history heightened the probability of positive answers. Most knew about some factors such as growing old, being pregnant when older than 30 years of age, brief periods of breast feeding, late menopause at age above 50, premature puberty, and low level of personal hygiene. Overall, $43 \%$ of respondents possessed reasonable knowledge of breast cancer in terms of knowing the symptoms, risk factors and breast examination (7).

In 2014, a study attempted to determine the awareness level of female university students from 24 middle and low income and emerging economic countries of breast cancer risks. A cross-sectional survey was executed with 10,242 undergraduate university students from 24 countries across Asia, Africa, and the America. Findings showed that $35.4 \%$ of the participants were unaware with the risk factors of breast cancer, $43.8 \%$ believed in having a genetic link, and only $12.5 \%$, $10.9 \%$ and $10.6 \%$ were able to determine that consumption of alcohol, excessive body weight, and lack of physical activity, were the risk factors causing cancer. Furthermore, 13.3\% indicated dietary fat and $11.5 \%$ fiber as influencers of breast cancer and suggested that low fat and high-fiber diets could possibly provide some modest level of protection against breast cancer. Smoking (19.4\%) and stress(13.5\%), although the most frequently indicated breast cancer risk factors in fact had less clear effect on breast cancer. Different nations exhibited different awareness levels, particular the genetic causes of breast cancer for females hailing from countries such as India, Madagascar, Ivory Coast, Laos and Nigeria. These countries exhibited 30\% less awareness than their female counterparts from Pakistan, Turkey, Singapore, Philippines and Grenada where it showed $60 \%$ or higher (29). Another study conducted to investigate 100 women in the Rural Community of Ondo State, Nigeria. Their mean age was 26 years. The risk factor most commonly quoted by participants was "Excessive alcohol consumption" (65\%), heavy cigarette smoking (60\%), and usage of skin color modifying cream and soap (45\%), as well as a sedentary lifestyle (30\%). Overall $45 \%$ of respondents had knowledge to a certain extent about the causes of the risk factors (recognizing two or more accepted causes of breast cancer). On the other hand, 50\% had standard knowledge (recognizing two or more accepted breast cancer risk factors). Even though $60 \%$ of participants had the belief that breast cancer could be minimized by employing a vaccine, only $34 \%$ realized that breast examination was a breast cancer prevention strategy. Around 55\% possessed the impression that exercise could prevent breast cancer, while $40 \%$ believed that the similar result could be obtained through dieting (30). Likewise, Vikas Fotedar et al. (2013) conducted a cross-sec- tional study for the purpose of assessing the extent of the knowledge of the participants about the study on breast cancer risk factors, early detection strategies, and screening methods. The participants were 457 nurses working in Indira who were aged 20 years and above. The findings revealed that averagely, only $49 \%$ of the entire population possessed minimum knowledge about the breast cancer risk factors. Additionally, $10 \%$ of the respondents possessed below level of knowledge and $25 \%$ of them possessed good knowledge, while $45 \%$ possessed standard knowledge and $16 \%$ of the respondents possessed extraordinary knowledge about risk factors of breast cancer and early detection approaches. Therefore, the study proposed the necessity of ongoing medical education campaigns on breast cancer at institutional level (31).

A study conducted among 1,315 Saudi adult females for the purpose of assessing the level to determine the knowledge about risk factors found in the use of screening methods for early detection of breast cancer among them. Results indicated that the level of knowledge in regards to risk factors and proper screening was below average and was dependent on the level of education and the occupational status. A positive family history was discovered in $18 \%$ of cases within the first and second degree relatives, and $2 \%$ possessed a pervious history of benign breast lesions. It reported that women, regardless of their extent of academic education, were not knowledgeable about breast cancer risk factors and were under-use of the recommendations for breast cancer screening (32).

\section{CONCLUSION}

There has risen the need to better educate younger women regarding breast cancer risk factors and screening practices, which would aid in lowering mortalities due to breast cancer globally. Current data shows that there is a gradual rise of breast cancer research, but is still greatly lacking, particularly in the areas of breast cancer screening which would enable detecting breast cancer early and reduce deaths among women. Thus, much more research is required to better understand the cultural behavior globally in educating the young adults given social sensitivities and effective intervention tactics.

Furthermore, the health education should be custom-made to comply with cultural norms and sensitivities within various parts of the globe, especially within young adults. Intensive educational campaigns should be undertaken to promote breast cancer awareness as well as how to prevent breast cancer, identify it early on and screen oneself through clinical breast examination and mammography. Health practitioners should also attempt to spread awareness about breast cancer as much as possible within their own capacity.

\section{REFERENCES}

1. Ferlay J, Soerjomataram I, Dikshit R, Eser S, Mathers C, Rebelo M, et al. Cancer incidence and mortality worldwide: sources, methods and major patterns in GLOBOCAN 2012. Int J cancer. 2015;136(5):E359-86.

2. Torre LA, Bray F, Siegel RL, Ferlay J, Lortet-Tieulent J, Jemal A. Global cancer statistics, 2012. CA Cancer J Clin. 2015;65(2):87-108. 
3. Sait WA, Al-Amoudi SM, Tawtai DA, Abduljabbar HS. The knowledge of breast cancer among young Saudi females. Saudi Med J. 2010;31(11):1242-4.

4. Anderson BO JR. Breast cancer issues in developing countries: an overview of the breast health global initiative. World J Surg. 2008;32:2579-85.

5. Mia MS. Knowledge, Attitude and Practice Regarding Breast cancer Among Medical Students of Bangladesh: A Protocol Study. Centre for the Public Health; 2007.

6. Akinola R, Wright $\mathrm{K}$, Osunfidiya O, Orogbemi O, Akinola O. Mammography and mammographic screening: are female patients at a teaching hospital in Lagos, Nigeria, aware of these procedures? Diagnostic Interv Radiol. 2011;17(2):125.

7. Saeed RS, Bakir YY, Ali LM. Are women in Kuwait aware of breast cancer and its diagnostic procedures. Asian Pac J Cancer Prev. 2014;15(15):6307-13.

8. Montazeri A, Vahdaninia M, Harirchi I, Harirchi AM, Sajadian A, Khaleghi F, et al. Breast cancer in Iran: need for greater women awareness of warning signs and effective screening methods. Asia Pac Fam Med. 2008;7(1):6.

9. Anderson BO, Yip C, Smith RA, Shyyan R, Sener SF, Eniu A, et al. Guideline implementation for breast healthcare in low-income and middle-income countries. Cancer. 2008;113(S8):2221-43.

10. Guvenc I, Guvenc G, Tastan S, Akyuz A. Identifying women's knowledge about risk factors of breast cancer and reasons for having mammography. Asian Pacific J Cancer Prev. 2012;13(8):4191-7.

11. UK cancer research. Breast cancer incidence statistics. http://www.cancerresearchuk.org/cancer-info/cancerstats/types/breast/incidence/\#age., 2012.

12. Ranasinghe HM, Ranasinghe N, Rodrigo C, Seneviratne RDA, Rajapakse S. Awareness of breast cancer among adolescent girls in Colombo, Sri Lanka: a school based study. BMC Public Health. 2013;13(1):1209.

13. Sociaty AC. Breast cancer Facts \& Figures. American Cancer Society; 2007.

14. Peacey V, Steptoe A, Davídsdóttir S, Baban A, Wardle J. Low levels of breast cancer risk awareness in young women: an international survey. Eur J Cancer. 2006;42(15):2585-9.

15. Sambanje MN, Mafuvadze B. Breast cancer knowledge and awareness among university students in Angola. Pan Afr Med J. 2012;11(1).

16. Karayurt Ö, Özmen D, Çetinkaya AÇ. Awareness of breast cancer risk factors and practice of breast self examination among high school students in Turkey. BMC Public Health. 2008;8(1):359.

17. Karayurt Ö, Dicle A, Malak AT. Effects of peer and group education on knowledge, beliefs and breast self-examination practice among university students in Turkey. Turkish J Med Sci. 2009;39(1):59-66.

18. Ahmadian M, Samah AA. Application of health behavior theories to breast cancer screening among Asian women. Asian Pacific J Cancer Prev. 2013;14(7):4005-13.

19. Yousuf SA, Al Amoudi SM, Nicolas W, Banjar HE, Salem SM. Do Saudi nurses in primary health care centres have breast cancer knowledge to promote breast cancer awareness? Asian Pac J Cancer Prev. 2012;13(9):4459-64.

20. Ahmed HG, Ashankyty IM, Alshammeri KJK, Alrashedi SA. Assessment of Breast cancer Awareness Level among Saudi Medical Students. 2017;7(4):4-8.

21. Segni MT, Tadesse DM, Amdemichael R, Demissie HF. Breast self-examination: knowledge, attitude, and practice among female health science students at Adama Science and Technology University, Ethiopia. Gynecol Obs. 2016;6(368):932-2161.

22. Younis M, Al-Rubaye D, Haddad H, Hammad A, Hijazi M. Knowledge and Awareness of Breast cancer among Young Women in the United Arab Emirates. Adv Breast cancer Res. 2016;5(4):163.

23. Akhtari-Zavare M, Latiff LA, Juni MH, Said SM, Ismail IZ. Knowledge of Female Undergraduate Students on Breast cancer and Breast Selfexamination in Klang Valley, Malaysia. Asian Pac J Cancer Prev. 2015;16(15):6231-5.

24. Liu L-Y, Wang F, Yu L-X, Ma Z-B, Zhang Q, Gao D-Z, et al. Breast cancer awareness among women in Eastern China: a cross-sectional study. BMC Public Health. 2014;14(1):1004.

25. Akhtari-Zavare M, Ghanbari-Baghestan A, Latiff LA, Matinnia N, Hoseini M. Knowledge of breast cancer and breast self-examination practice among Iranian women in Hamedan, Iran. Asian Pac J Cancer Prev. 2014;15(16):6531-4.

26. Isara AR, Ojedokun CI. Knowledge of breast cancer and practice of breast self examination among female senior secondary school students in Abuja, Nigeria. J Prev Med Hyg. 2011;52(4).

27. Alrashidi AG, Ahmed HG, Alshammeri KJK, Alrashedi SA, ALmutlaq BA, Alshammari FNM, et al. Knowledge and Perceptions of Common Breast cancer Risk Factors in Northern Saudi Arabia. Asian Pacific J Cancer Prev. 2017;18(10):2755-61.

28. Mumtaz Y, Iqbal N, Masood F, Raza L. Awareness Regarding Breast cancer a Global Health Problem-A Study amongst Adult Women in Karachi. Ann Abbasi Shaheed Hosp Karachi Med Dent Coll. 2017;22(2).

29. Peltzer K, Pengpid S. Awareness of breast cancer risk among female university students from 24 low, middle income and emerging economy countries. Asian Pac J Cancer Prev. 2014;15(18):7875.

30. Makanjuola OJ, Amoo PO, Ajibade BL, Makinde OY. Breast cancer: knowledge and practice of breast self examination among women in rural community of Ondo State, Nigeria. IOSR J Pharm Biol Sci. 2013;8(1):32-7.

31. Fotedar V, Seam RK, Gupta MK, Gupta M, Vats S, Verma S. Knowledge of risk factors \& early detection methods and practices towards breast cancer among nurses in Indira Gandhi Medical College, Shimla, Himachal Pradesh, India. Asian Pacific J Cancer Prev. 2013;14(1):117-20.

32. Amin TT, Al Mulhim AR, Al Meqihwi A. Breast cancer knowledge, risk factors and screening among adult Saudi women in a primary health care setting. Asian Pac J Cancer Prev. 2009;10(1):133-8. 